\title{
Analysis of nonideality: insights from high concentration simulations of sedimentation velocity data
}

\author{
J. J. Correia ${ }^{1}$ (D) R. T. Wright ${ }^{2} \cdot$ P. J. Sherwood ${ }^{3} \cdot$ W. F. Stafford ${ }^{4}$
}

Received: 15 July 2020 / Revised: 22 September 2020 / Accepted: 19 October 2020 / Published online: 6 November 2020

(c) The Author(s) 2020

\begin{abstract}
The Aviv fluorescence detection system (Aviv-FDS) has allowed the performance of sedimentation velocity experiments on therapeutic antibodies in highly concentrated environments like formulation buffers and serum. Methods were implemented in the software package SEDANAL for the analysis of nonideal, weakly associating AUC data acquired on therapeutic antibodies and proteins (Wright et al. Eur Biophys J 47:709-722, 2018, Anal Biochem 550:72-83, 2018). This involved fitting both hydrodynamic, $k_{s}$, and thermodynamic, $\mathrm{BM}_{1}$, nonideality where concentration dependence is expressed as $s=s^{0} /\left(1+k_{s} c\right)$ and $D=D^{\mathrm{o}}\left(1+2 \mathrm{BM}_{1} c\right) /\left(1+k_{s} c\right)$ and $s^{\mathrm{o}}$ and $D^{\mathrm{o}}$ are values extrapolated to $c=0(\mathrm{mg} / \mathrm{ml})$. To gain insight into the consequences of these phenomenological parameters, we performed simulations with SEDANAL of a monoclonal antibody as a function of $k_{s}(0-100 \mathrm{ml} / \mathrm{g})$ and $\mathrm{BM}_{1}(0-100 \mathrm{ml} / \mathrm{g})$. This provides a visual understanding of the separate and joint impact of $k_{s}$ and $\mathrm{BM}_{1}$ on the shape of high-concentration sedimentation velocity boundaries and the challenge of their unique determination by finite element methods. In addition, mAbs undergo weak self- and hetero-association (Yang et al. Prot Sci 27:1334-1348, 2018 ) and thus we have simulated examples of nonideal weak association over a wide range of concentrations (1-120 mg/ $\mathrm{ml}$ ). Here we demonstrate these data are best analyzed by direct boundary global fitting to models that account for $k_{s}, \mathrm{BM}_{1}$ and weak association. Because a typical clinical dose of $\mathrm{mAb}$ is $50-200 \mathrm{mg} / \mathrm{ml}$, these results have relevance for biophysical understanding of concentrated therapeutic proteins.
\end{abstract}

Keywords 2nd Virial coefficient · Diffusion · Hydrodynamic nonideality · Sedimentation velocity · Thermodynamic nonideality

Special Issue: Analytical Ultracentrifugation 2019.

Electronic supplementary material The online version of this article (https://doi.org/10.1007/s00249-020-01474-5) contains supplementary material, which is available to authorized users.

\section{J. J. Correia}

jcorreia@umc.edu

1 Department of Cell and Molecular Biology, University of MS Medical Center, Jackson, MS, USA

2 Biophysics Group, Janssen Biotherapeutics, Spring House, PA, USA

3 Interactive Technology, Oakland, CA, USA

4 Department of Systems Biology, Harvard Medical School, Boston, MA, USA

\section{Introduction}

There is great interest in the biotechnology field in studying high concentration therapeutic monoclonal antibody (mAb) solutions. Monoclonal antibodies are typically administered by IV or subcutaneous (SC) injection at high concentrations (Rituxan: $10 \mathrm{mg} / \mathrm{ml}$; Avastin: $25 \mathrm{mg} / \mathrm{ml}$; Simponi: $100 \mathrm{mg}$ / $\mathrm{ml}$; Humira: $100 \mathrm{mg} / \mathrm{ml}$; Herceptin: $150 \mathrm{mg} / \mathrm{ml}$; Xolair: $150 \mathrm{mg} / \mathrm{ml}$ ). This requires that $\mathrm{mAbs}$ be highly soluble and stable under formulation conditions. Analytical Ultracentrifugation (AUC) sedimentation velocity (SV) is highly appropriate for studying $\mathrm{mAbs}$ because it can reveal the presence of unfolding, dissociation, aggregation and undesirable reversible association over a wide range of concentrations (Berkowitz 2006; Philo 2009; Liu et al. 2005). To address the needs of therapeutic protein development, experiments at high concentration and in complex solution environments are required (Shire et al. 2004; Liu et al. 2015). The fluorescence detection system (FDS) developed by Tom Laue and 
colleagues (MacGregor et al. 2004; Kroe and Laue 2009; Kingsbury and Laue 2011) and, until recently, available from Aviv, is an extremely useful technique for studying high concentrations and heterogeneous systems like serum. FDS experiments with mAbs in serum can reveal unusual interactions that do not occur in typical formulation buffer conditions (Demeule et al. 2009). Nonideality is represented by the following phenomenological equations for sedimentation and diffusion (Fujita 1962).

$s=\frac{s^{\mathrm{o}}}{1+k_{s} c}$ and

$D=\frac{D^{\mathrm{o}}\left(1+2 B M_{1} c\right)}{\left(1+k_{s} c\right)}$

In these equation $s^{\mathrm{o}}$ and $D^{\mathrm{o}}$ are values extrapolated to zero protein concentration, $c$ is concentration in $\mathrm{mg} / \mathrm{ml}, k_{s}$ is hydrodynamic nonideality and $\mathrm{BM}_{1}$ is thermodynamic nonideality (the 2 nd virial coefficient $B$ times molecular weight), both expressed as $\mathrm{ml} / \mathrm{mg}$ to match the units of concentration. The antibody field has used orthogonal techniques like static light scattering (SLS) to measure a second virial coefficient, $\mathrm{BM}_{1}$, and DLS to measure concentration dependence of diffusion, $k_{D}$. This is typically summarized as $k_{D}=\mathrm{BM}_{1}-k_{s}$ (Harding and Johnson 1985) suggesting concentration dependence of diffusion involves both a hydrodynamic and thermodynamic component. Many studies combined light scattering, AUC and DLS to investigate the behavior of antibody solutions, emphasizing the complementary information gathered on nonideality and, where present, association (Solovyova et al. 2001; Saluja et al. 2010; Yadav et al. 2011a, b). The goal in part is to survey formulation conditions for the presence of aggregation (Saluja et al. 2010), the avoidance of high viscosity (Yadav et al. 2012), or conditions that favor crystallization (Solovyova et al. 2001). The discussion often focuses on the algebra, do $k_{s}+k_{D}$ equal $\mathrm{BM}_{1}$, and the problems with subtracting small values, $\mathrm{BM}_{1}-k_{s}$, that nearly cancel. This algebraic expression shown above is valid only in the absence of association. Thus, if $k_{s}, k_{D}$ and $\mathrm{BM}_{1}$ are negative, a nonideal association model should be implemented, such that the nonideality and the association contributions can be accounted for separately. This is generally not feasible by DLS and/or not implemented by SLS methods. The analysis of weak, nonideal association and the extraction of both nonideality and association constants by AUC methods is challenging; it cannot be done with distribution analysis (Rowe 2011; Wright et al. 2018a). On the other hand, rigorous analysis requires nonlinear least squares (NLLS) global fitting of AUC SV data sets to an explicit model that includes both nonideality $\left(k_{s}\right.$ and $\left.\mathrm{BM}_{1}\right)$ and association. This approach is feasible in SEDANAL because of the ModelEditor feature that allows one to construct any number of simple or complex nonideal associating fitting models (Stafford and Sherwood 2004; Correia and Stafford 2015; Sherwood and Stafford 2016).

Here we present a series of simulations of the impact of $k_{s}$ and $\mathrm{BM}_{1}$ on high concentration antibody solutions of the therapeutic IgG Simponi. We present this over a range of values $(0-100 \mathrm{ml} / \mathrm{g})$ individually, $k_{s}$ and $\mathrm{BM}_{1}$ alone, and together, both $k_{s}$ and $\mathrm{BM}_{1}$, to allow a basis set of features that reveal their impact on SV boundary shape. We then choose realistic $k_{s}$ and $\mathrm{BM}_{1}$ values, and simulate a wide range of protein concentrations $(1-120 \mathrm{mg} / \mathrm{ml})$ that overlap Simponi's SC therapeutic dose, $100 \mathrm{mg} / \mathrm{ml}$, and demonstrate the range of data feasible for experimental determinations. Finally, in three recent studies, we showed that all mAb IgG's weakly self-associate and hetero-associate with other classes of IgG (Wright et al. 2018a, b; Yang et al. 2018). Thus, we present here simulations of nonideal, weak association to demonstrate the challenge of dissecting out basis sets for $k_{s}, \mathrm{BM}_{1}$ and association. This analysis has been possible with SEDANAL for a decade. The full power of the method required the implementation of features first described by Todd and Haschemeyer (1981), and this only recently was included in SEDANAL version 6.97 and above. These simulations provide graphical and conceptual insight for AUC users, and encourage the use of rigorous and robust global direct boundary fitting methods for nonideal, weakly associating systems.

\section{Methods}

Simulations were performed with SEDANAL, version 6.97 or later, a software package developed to fit AUC data for complex, nonideal associating systems (Stafford and Sherwood 2004). The models simulated include $k_{s}$ (hydrodynamic nonideality), $\mathrm{BM}_{1}$ (thermodynamic nonideality), and weak self-association, represented here as dimerization, $K_{2}$. The mAb modeled is golimumab or Simponi, with a molecular weight of 146,909 , an extrapolated $s^{0}=6.6 \mathrm{~s}$, an experimentally measured buoyancy $(1-\nu \rho)$ of 0.26623 . Simulations in absorbance mode were done with no added noise. Since in silico absorbance or interference experiments are not limited by optical constraints, we adjusted the extinction coefficient for different path cells and present normalized plots. Data were simulated with 1500 points, and output with 650 points between 5.9 and $7.2 \mathrm{~cm}$ to match typical absorbance experiments.

Simulations of FDS tracer mode were done by setting the signal strength (extinction coefficient $\times$ quantum yield, referred to here as $\varepsilon_{1}$ ) for monomer at $1 \mathrm{mg} / \mathrm{ml}$ to 1000. To produce a constant signal in tracer mode each apparent extinction coefficient was calculated as $1000 / c_{0}$, where $c_{\mathrm{o}}$ is in $\mathrm{mg} / \mathrm{ml}$. For example, cell 2 is $5 \mathrm{mg} / \mathrm{ml}$ so 
$\varepsilon_{2}=1000 / 5=200$; cell 3 is $10 \mathrm{mg} / \mathrm{ml}$ so $\varepsilon_{3}=100$; cell 9 is $120 \mathrm{mg} / \mathrm{ml}$ so $\varepsilon_{9}=8.333$. All FDS simulations have added Gaussian noise of 10 corresponding to $1 \%$ of signal. SEDANAL global fitting of these data sets uses $\sim 60-100$ scans per data set, which amounts to up to 200,000 total data points, using the Levenberg-Marquardt algorithm to minimize standard deviation. Experimental in vitro or in serum optical constraints are addressed in the discussion.

Values of $k_{s}$ and $\mathrm{BM}_{1}$ were varied over a wide range $(0-100 \mathrm{ml} / \mathrm{g})$ to investigate and display their impact on boundary shapes. Experimentally we have shown that Simponi exhibits $k_{s}$ and $\mathrm{BM}_{1}$ values of $\sim 10 \mathrm{ml} / \mathrm{g}$ (Wright et al. 2018b). (SEDANAL internally uses concentration units of $\mathrm{mg} / \mathrm{ml}$ and thus $k_{s}$ and $2 \mathrm{BM}_{1}$ have units of $\mathrm{ml} / \mathrm{mg}$ to make $k_{s} c$ or $2 \mathrm{BM}_{1} \mathrm{c}$ dimensionless (Eqs. 1 and 2). However, the field uses ml/g (Rowe 1977; Harding and Johnson 1985; Solovyova et al. 2001; Saluja et al. 2010; Yadav et al. $2011 \mathrm{a}, \mathrm{b}$ ) and thus we plot data vs $\mathrm{mg} / \mathrm{ml}$, but report data in units of $\mathrm{ml} / \mathrm{g}$ (Table 1 ). This avoids reporting numbers with lots of digits $(0.010 \mathrm{ml} / \mathrm{mg}$ vs $10.0 \mathrm{ml} / \mathrm{g})$.) Thus, we also separately constrained $k_{s}$ and $\mathrm{BM}_{1}$ to $10 \mathrm{ml} / \mathrm{g}$ and varied total concentration from 1 to $120 \mathrm{mg} / \mathrm{ml}$. Weak self- and hetero-association of therapeutic $\mathrm{mAbs}$ has been demonstrated (Wright et al. 2018a,b; Yang et al. 2018), and is assumed to be dimerization because of the small extent of reaction. The goal of these simulations was to present graphical basis sets that demonstrate the impact of $k_{s}$ and $\mathrm{BM}_{1}$ on boundary shapes. Thus, simulations are initially presented over a wide range of values to give a picture of what nonideality looks like in an experimental setting. Simulations were also performed at fixed values of $k_{s}$ and $\mathrm{BM}_{1}$ and as a function of concentration (1-120 mg/ $\mathrm{ml})$ to mimic therapeutic samples and to establish what is required to extract experimental values of the parameters. We observed that all mAbs self-associate and heteroassociate with other antibodies. To explore this, nonideal association $\left(k_{s}, \mathrm{BM}_{1}, K_{2}\right)$ simulations as a function of small $K_{2}$ values are presented. In addition, all mAbs contain small amounts of dimeric and trimeric aggregates, and these are included in the model to mimic realistic heterogeneity.

All $k_{s}$ and $\mathrm{BM}_{1}$ values are provided as matrices, with elements, $k_{i j}$ and $B_{i j} M_{i}$, representing self- and cross-term interactions (Table S1 and S2; Correia and Stafford 2015; Wright et al. 2018a). This represents a family of phenomenological equations for each component that explicitly includes all species concentrations. For example, $s_{1}$ (or $s_{A}$ ) can be written

$s_{1}=\frac{s_{1}^{\mathrm{o}}}{1+k_{11} c_{1}+k_{12} c_{2}+k_{13} c_{3}}$

where $c_{2}$ corresponds to dimer concentrations, $c_{3}$ to trimer concentrations, and $k_{12}$ and $k_{13}$ are cross-term nonideality terms reflecting the effect of dimer and trimer concentrations on monomer $s_{1}$. Other species like reversible dimers or irreversible dimers and trimers have similar expressions (see Supplemental equations S1-S4). In addition, $D_{1}\left(\right.$ or $\left.D_{A}\right)$ can be written

$\mathrm{D}_{1}=\frac{\mathrm{D}_{1}^{\mathrm{o}}\left(1+2 B_{11} M_{1} c_{1}+2 B_{12} M_{2} c_{2}+2 B_{13} M_{3} c_{3}\right)}{\left(1+\mathrm{k}_{11} \mathrm{c}_{1}+\mathrm{k}_{12} \mathrm{c}_{2}+\mathrm{k}_{13} \mathrm{c}_{3}\right)}$

with similar expressions for dimers and trimers (Correia and Stafford 2015; Stafford 2016). Note we assume the cross terms $k_{i j}$ and $B_{i j} M_{j}$ for dimers and trimers are the same as monomers on a weight scale; this is reasonable since experimentally $\mathrm{mAb}$ aggregates have the same frictional ratio, $f / f_{\mathrm{o}}$ (Philo 2003), but this is adjustable in the matrix if required. (See Supplemental Methods section for more details.)

SEDANAL simulates and fits SV data by the method of Claverie (1976) which uses finite-element solutions to the Lamm equation, the partial differential equation that

Table 1 SEDANAL analysis of high concentration FDS data

\begin{tabular}{|c|c|c|c|c|c|}
\hline \multicolumn{2}{|l|}{ Concentrations } & \multicolumn{2}{|c|}{$k_{s} \mathrm{ml} / \mathrm{g}$} & $\mathrm{BM}_{1} \mathrm{ml} / \mathrm{g}$ & $\mathrm{rms}$ \\
\hline \multicolumn{6}{|c|}{$\mathrm{ABC} K_{s} \mathrm{BM}_{1}$ model } \\
\hline $1-120 \mathrm{mg} / \mathrm{ml}$ & $6.5994(0.007 \%)$ & \multicolumn{2}{|c|}{$10.0(0.025 \%)$} & $9.99(0.137 \%)$ & 14.153 \\
\hline $1-40 \mathrm{mg} / \mathrm{ml}$ & $6.5996(0.008 \%)$ & \multicolumn{2}{|c|}{$10.00(0.06 \%)$} & $10.00(0.458 \%)$ & 14.145 \\
\hline $1-20 \mathrm{mg} / \mathrm{ml}$ & $6.5997(0.009 \%)$ & \multicolumn{2}{|c|}{$10.00(0.10 \%)$} & $10.04(0.94 \%)$ & 14.161 \\
\hline Concentrations & $s$ & $k_{s} \mathrm{ml} / \mathrm{g}$ & $\mathrm{BM}_{1} \mathrm{ml} / \mathrm{g}$ & $K_{2} \mathrm{M}^{-1}$ & $\mathrm{rms}$ \\
\hline \multicolumn{6}{|c|}{$\mathrm{AA}_{2} \mathrm{BC} k_{s} \mathrm{BM}_{1} K_{2}$ model } \\
\hline $1-120 \mathrm{mg} / \mathrm{ml}$ & $6.5989(0.013 \%)$ & $10.00(0.08 \%)$ & $10.06(0.22 \%)$ & $5008(0.34 \%)$ & 14.106 \\
\hline $1-40 \mathrm{mg} / \mathrm{ml}$ & $6.5993(0.019 \%)$ & $9.99(0.17 \%)$ & $9.93(0.67 \%)$ & $4998(0.38 \%)$ & 14.116 \\
\hline $1-20 \mathrm{mg} / \mathrm{ml}$ & $6.5991(0.025 \%)$ & $10.00(0.25 \%)$ & $9.993(1.94 \%)$ & $5006(0.56 \%)$ & 14.106 \\
\hline
\end{tabular}

$\mathrm{ABC}$ model is a monomer-aggregated dimer-aggregated trimer model plus nonideality. $\mathrm{AA}_{2} \mathrm{BC}$ model is the same model plus a reversible monomer-dimer association. Values in parentheses correspond to fractional error determined by a bootstrap analysis and correspond to one standard deviation 
describes simultaneous sedimentation and diffusion in a sector shaped cell (Todd and Haschemeyer 1981).

$\left(\partial c_{i} / \partial t\right)_{r}=-\frac{\partial}{r \partial r}\left[c_{i} \omega^{2} s_{i}\left(c_{i}\right) r^{2}-D_{i}\left(c_{i}\right) r\left(\frac{\partial c_{i}}{\partial r}\right)_{t}\right]$

The $s_{i}$ and $D_{i}$ terms are concentration-dependent and defined as above (Eqs. 3 and 4) to reflect nonideal behavior. If $\mathrm{mAb}$ samples are heterogeneous, paucidisperse systems and contain small amounts of dimeric or trimeric aggregates, simultaneous Lamm equations for the dimer and trimer are solved (Correia and Stafford 2015). Reversible association is included by adding a relationship that links dimer concentration to monomers through equilibrium or kinetic rate constants (Stafford and Sherwood 2004). Figure 1 presents an example of a SEDANAL fitter model for simulation. All antibody samples contain small amounts of irreversible dimer and trimer aggregates, set here to $10 \%$ and $5 \%$ weight fraction. In addition, antibodies can undergo reversible nonideal association represented here as monomer-dimer $\left(\mathrm{AA}_{2}\right)$ plus $k_{s}$ and $\mathrm{BM}_{1}$. Thus, in this model system, $\mathrm{AA}_{2}$ refers to reversible dimer formation and $\mathrm{BC}$ or dimer aggregates and trimer aggregates refers to irreversible dimers and trimers.

High concentration solutions to the Lamm equation are intrinsically unstable, primarily due to numerical instability in the base region of the cell (SEDANAL detects this as a "Check Grid" error). Todd and Haschemeyer (1981) were the first to develop curve-fitting methods using Claverie's rapid numerical solutions to the Lamm equation; the Claverie method was for comparing simulations to real data (Claverie 1976). We constrained parameters to deal with this instability. The most significant of these are defined as $\varepsilon$ (epsilon) and $\eta$ (eta), where $s / s_{0}=1-\varepsilon$ and $D / D_{\mathrm{o}}=1-\eta$ (Eqs. 3 and 4). For realistic parameters, meaning $k_{s}$ and $\mathrm{BM}_{1}$ equal and positive, $D / D_{\mathrm{o}}<2$ (Figure $\mathrm{S} 1 \mathrm{~A}$ ); other choices give less restrictive ranges (Figure

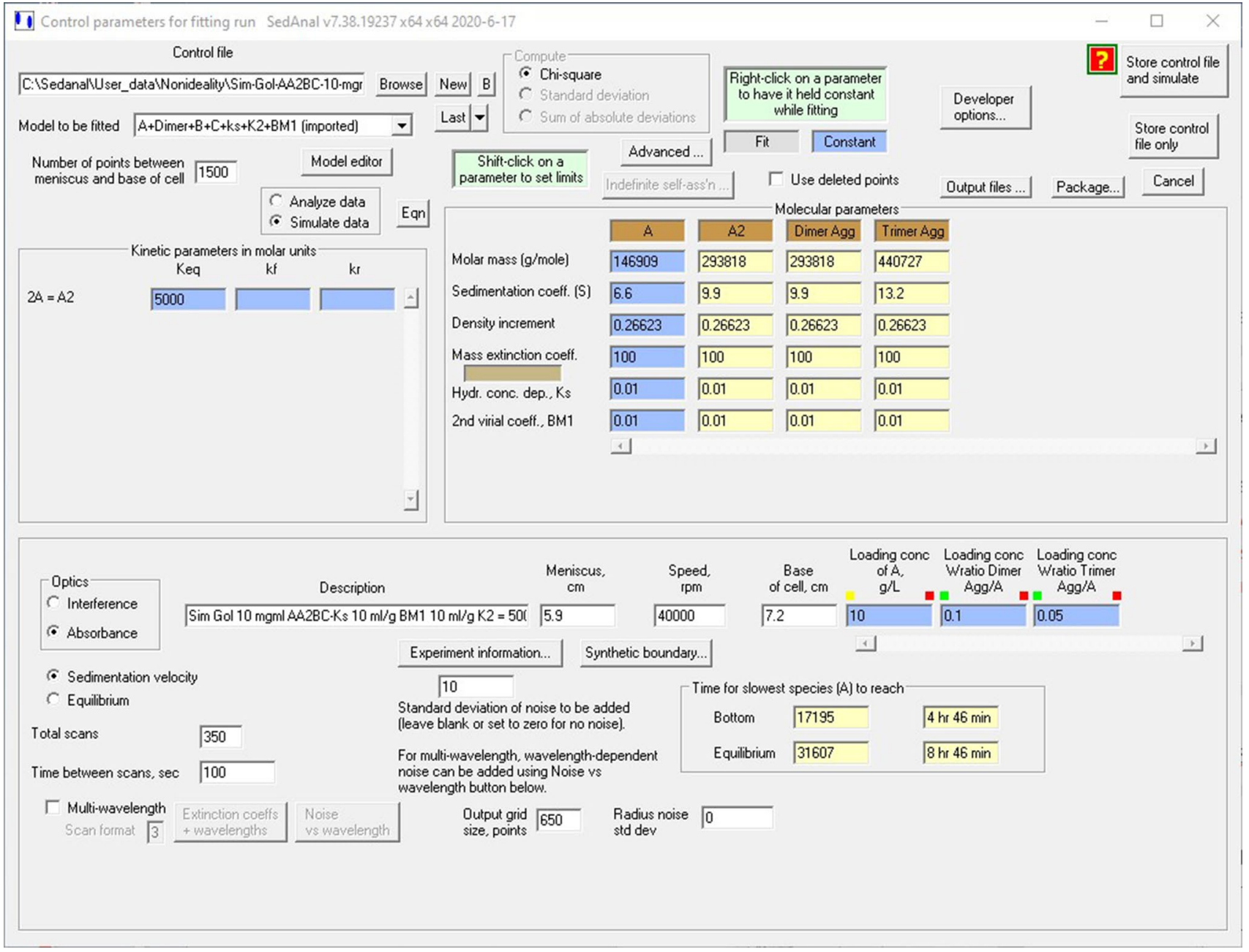

Fig. 1 Screen shot of a SEDANAL AUC SV simulation of Simponi at $40 \mathrm{~K} \mathrm{rpm}, 10 \mathrm{mg} / \mathrm{ml}$, with $k_{s}=0.01 \mathrm{ml} / \mathrm{mg}, \mathrm{BM}_{1}=0.01 \mathrm{ml} / \mathrm{mg}$, and $K_{2}=5000 \mathrm{M}^{-1}$, with $10 \%$ dimer and $5 \%$ trimer. Other details are visible in the figure 
S1B). These constraints are provided to the SEDANAL fitter to set the upper limit on $D / D_{0}$. SEDANAL also allows concentrations at the base to be limited.

We restrict $k_{s}$ and $\mathrm{BM}_{1}$ to positive values because negative values imply association, and therefore, nonideal associating systems are modeled by an explicit nonideal, association scheme (see Fig. 1). Otherwise, the magnitude of $k_{s}$ and $\mathrm{BM}_{1}$ reflect the sum of multiple attractive and repulsive interactions and are difficult to interpret (Laue 2012; Wright et al. 2018b; Laue and Shire 2020). Sedimentation and diffusion coefficients vary across the cell due to nonideality and to local changes in concentration as the boundary components sediment and fractionate (Figure S2). This fractionation or boundary separation has been called demixing by Kingsbury and Laue (2011). This variation in the effect of nonideality is especially true in the base region, where concentrations can increase by two or more orders of magnitude, and calculations of concentration become numerically unstable. SEDANAL has been upgraded to handle these effects (Todd and Haschemeyer 1981), and all the data simulated and fit in this study exhibited stable solutions.

Simulated data are analyzed by Wide Distribution Analysis (WDA) an option in SEDANAL, and plotted as $s^{*} g\left(s^{*}\right)$ vs $\log \left(s^{*}\right)$. This transformation follows from the definition of $g\left(s^{*}\right)=\mathrm{d} c / \mathrm{d} s$; thus $s^{*} \mathrm{~d} c / \mathrm{d} s^{*}=\mathrm{d} c / \mathrm{d}\left(\ln \left(s^{*}\right)\right)$ (Stafford and Braswell 2004; Sherwood and Stafford 2016). WDA was developed for multi-speed experiments but we have found it useful for rapid analysis of singlespeed runs as well. We plot data as normalized $s^{*} g\left(s^{*}\right)$ vs $\log \left(s^{*}\right)$ for convenient reading of the scale and for direct comparison of trends in the distributions. The WDA method allows all data scans to be included, with early scans providing information about large components (out to $1000 \mathrm{~S}$ in these simulations), and late scans providing information about small species. One can choose different radial positions to view sedimentation at different extents of resolution (Figure S3). A standard DCDT analysis (Stafford 1992) cannot mimic this degree of resolution because it is limited to a narrow span of data scans, in this case a region where the monomer boundary is near 6.4-6.5 cm. Nonetheless, DCDT ${ }^{+}$analysis (Stafford 1992; Philo 2006) can be compared with $s^{*} g\left(s^{*}\right)$ (Figure S4) to reveal the precision and advantages of both methods. $\mathrm{DCDT}^{+}$and WDA generate $s_{\mathrm{w}}$ and integrated signal area under the curve from results extrapolated to the initial concentration, $c_{\mathrm{o}}$ (Kegeles and Gutter 1951; Patel et al. 2018). Both methods are used to construct $1 / s_{\mathrm{w}}$ vs $c$ plots (Figs. 6 and 10) to explore the limitations of linear graphical analysis.

\section{Results}

Figure 2 shows a family of simulations performed at $10 \mathrm{mg} / \mathrm{ml}$ and over the $k_{s}$ range $0-100 \mathrm{ml} / \mathrm{g}$. This corresponds to a $k_{11} c_{1}$ range, $\mathrm{ml} / \mathrm{mg}$ times $\mathrm{mg} / \mathrm{ml}$, of 0.01 to 1.0 at $c_{\mathrm{o}}$, or an initial $s_{\text {app }}$ range of 6.6-3.3 s. Thus, the monomer boundary slows, and, since $\left(1+k_{11} c_{1}\right)$ is also in the denominator for $D$ (Eq. 2), the monomer boundary is sharper. Note, the concentrations vary with radial position and time in the simulation due to demixing and radial dilution, and thus the exact $s_{\text {app }}$ correction is a function of radial position and time throughout the cell and involves contributions from monomer, dimer and trimer species, $s_{i}=\left(1+k_{i 1} c_{1}+k_{i 2} c_{2}+k_{i 3} c_{3}\right)$ (Figure $\left.\mathrm{S} 2\right)$. The boundaries for dimer and trimer sediment in the plateau region of the monomer, and are thus dominated by the $k_{i j}$ cross terms for the larger monomer concentration. Note that the aggregate peak widths do not change significantly because they are in the presence of a nearly constant concentration of monomer. This is in contrast to the monomer boundary where low concentration on the centripetal side of the boundary speeds up sedimentation, and high concentration on the centrifugal side slows sedimentation leading to sharpening, increased concentration and a negative concentration gradient. This is the classic Johnston-Ogston (JO) effect (Johnston and Ogston 1946; Correia et al. 1976, 2016). Oddly enough, even at $10 \%$ dimer, the JO effect is evident

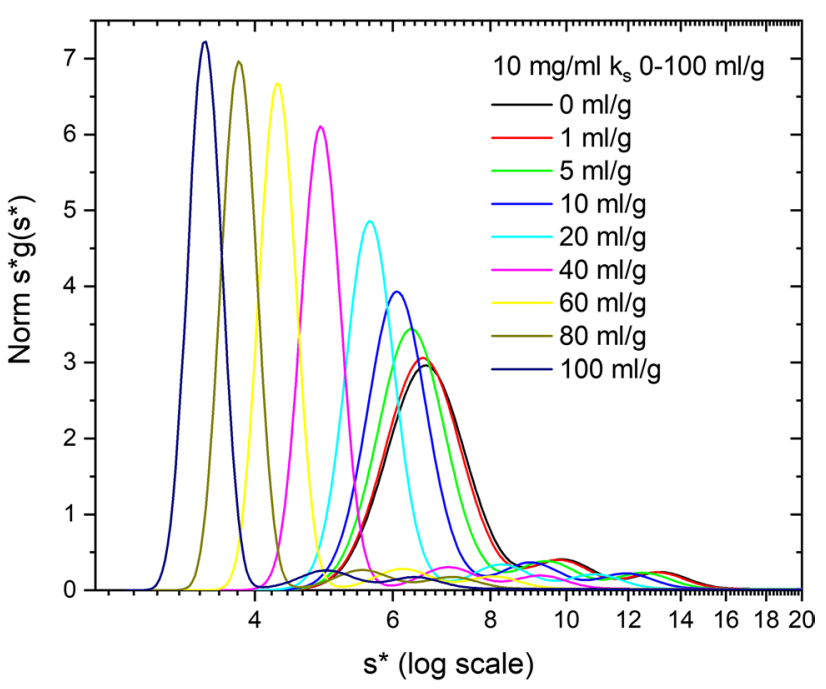

Fig. 2 Simulation of $\mathrm{ABC}$ or monomer-dimer-trimer model, at $10 \mathrm{mg} / \mathrm{ml} \mathrm{Simponi} \mathrm{plus} \mathrm{10 \%} \mathrm{dimer} \mathrm{and} \mathrm{5 \%} \mathrm{trimer} \mathrm{irreversible} \mathrm{aggre-}$ gates, where all $k_{i j}$ values (self and cross term; Table S1) vary from 0 to $100 \mathrm{ml} / \mathrm{g}$. Data are plotted as normalized $s^{*} g\left(s^{*}\right)$ vs $s^{*}$ on a $\log$ scale 
in the monomer boundary as it interacts with the dimer boundary (Figure S2). The JO effect is more pronounced at both high $k_{s}$ and high concentrations since it is due to a product, $k_{s} c$.

Typical $k_{s}$ values for $\mathrm{mAbs}$ are $4-11 \mathrm{ml} / \mathrm{g}$ (Wright et al. 2018b; Yang et al. 2018). However, experimentally $k_{s}$ is known to increase dramatically for asymmetric proteins (Creeth and Knight 1965). For example, fibrinogen is $15.5 \mathrm{ml} / \mathrm{g}$; TMV is $33.8 \mathrm{ml} / \mathrm{g}$; myosin is $49-73 \mathrm{ml} / \mathrm{g}$; collagen is $265 \mathrm{ml} / \mathrm{g}$. Pegylated proteins (Li et al. 2012) and IDPs like ELP (Correia et al. 2016) also have very large $k_{s}$ values. Thus, Fig. 2 demonstrates a wide range of expected behaviors for compact to moderately asymmetric proteins.

Figure 3 shows a family of simulations performed at $10 \mathrm{mg} / \mathrm{ml}$ and over the $\mathrm{BM}_{1}$ range $0-100 \mathrm{ml} / \mathrm{g}$. Since $\mathrm{BM}_{1}$ only influences $D$, the boundary spreads, the peak position drifts, but on average does not sediment differently $\left(S_{\mathrm{w}}=7.12 \mathrm{~s} \pm 0.019 \mathrm{~s}\right.$ or $\left.0.27 \%\right)$. This corresponds to a $2 B_{11} M_{1} c_{1}$ range, $\mathrm{ml} / \mathrm{mg}$ times $\mathrm{mg} / \mathrm{ml}$, of $0.02-2.0$ at $c_{0}$, or an initial $D / D_{\mathrm{o}}$ range of $1-3$ corresponding to the $\left(1+B_{i j} M\right.$ ${ }_{j} c_{j}$ ) term. Note the broadening of the monomer region and an equal degree of broadening of the dimer and trimer regions due to cross term nonideality. This will reduce the resolution of these minor peaks for single sample analysis. Also note this broadening in the monomer region makes the boundary appear more heterogeneous (see "Discussion").

Both $k_{s}$ and $\mathrm{BM}_{1}$ are caused by a combination of excluded volume, charge and shape effects (Tanford 1961; Rowe 1977). As discussed above and in the literature, $k_{s}$ and $\mathrm{BM}_{1}$ have similar magnitudes, and thus this range of values is reasonable in principle (Yadev et al. 2012; Wright et al. 2018b; Chaturvedi et al. 2019; Chaturvedi and Schuck 2019). To

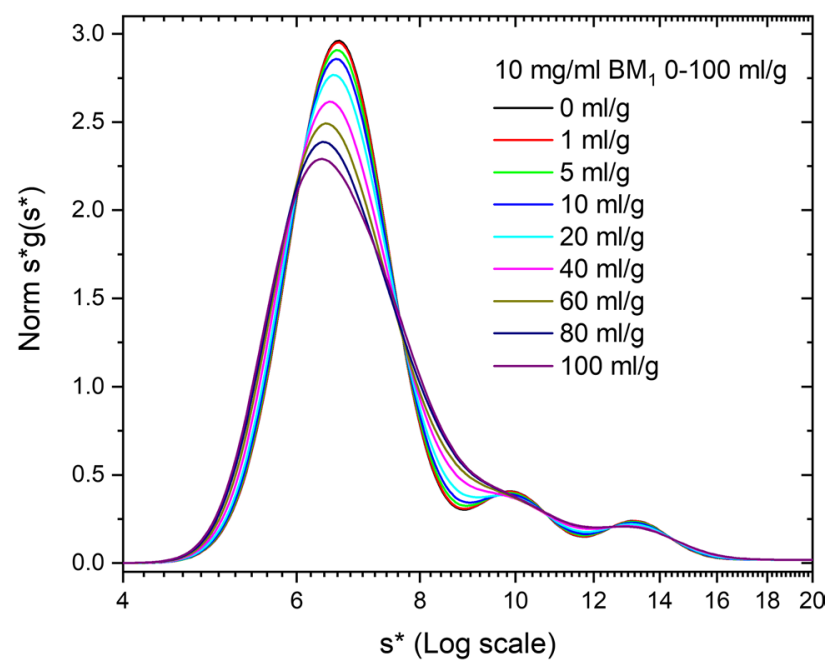

Fig. 3 Simulation of ABC model, at $10 \mathrm{mg} / \mathrm{ml} \mathrm{Simponi} \mathrm{plus} 10 \%$ dimer and $5 \%$ trimer aggregates, where all $B_{i j} M_{j}$ values (self and cross term) vary from 0 to $100 \mathrm{ml} / \mathrm{g}$. Data are plotted as normalized $s^{*} g\left(s^{*}\right)$ vs $s^{*}$ on a $\log$ scale demonstrate this similarity we simulate $10 \mathrm{mg} / \mathrm{ml} \mathrm{Sim-}$ poni and vary both $k_{i j}$ and $B_{i j} M_{j}$ equally from 0 to $100 \mathrm{ml} / \mathrm{g}$ (Fig. 4). This range of parameter values should impact $s$ values in a manner similar to Fig. 2, but $D$ values now have changes to both the numerator and denominator that offset each other (Eq. 4). In this case the ratio $\left(1+B_{11} M c_{1}\right) /$ $\left(1+k_{11} c_{1}\right)$ will vary from 1 to 1.5 , but as described above the concentrations of all species vary with radial position and time in the run due to demixing and radial dilution, and thus the exact $D / D_{\mathrm{o}}$ value is a function of radius and time throughout the cell (Eq. 4). This increase in $D / D_{\mathrm{o}}$ causes the dimer and trimer regions to broaden and thus reduces the resolution of the dimer and trimer peaks. Note also that these data exhibit a JO effect at the monomer-dimer interface in a concentration-dependent manner according to the value of $k_{i j}$ cross terms (Figure S2).

These first three sets of simulations (Figs. 2, 3 and 4) vary nonideality at a fixed protein concentration. Figure 5 shows concentration-dependent simulations of Simponi from 1 to $120 \mathrm{mg} / \mathrm{ml}$ plus $10 \%$ dimer and $5 \%$ trimer aggregates. (Figure S6A presents the $\mathrm{DCDT}^{+} g\left(s^{*}\right)$ vs $s^{*}$ version of this plot). Nonideality parameters, $k_{i j}$ and $B_{i j} M_{j}$, (self and cross term) are constrained to experimentally reasonable values of $10 \mathrm{ml} / \mathrm{g}$ (Wright et al. 2018a). The increase in hydrodynamic nonideality reduces $s_{\text {app }}$ in a manner similar to Fig. 2. The ratio of thermodynamic to hydrodynamic terms $\left(1+2 B_{i j} M_{j} c\right) /\left(1+k_{i j} c\right)$ in the plateau region of the simulations increases $D / D_{\mathrm{o}}$ from 1.01 to 1.58 . This is most evident in the dimer and trimer zones where discrete peaks are broadened and more difficult to resolve. As the protein sediments the concentration dramatically increases at the base

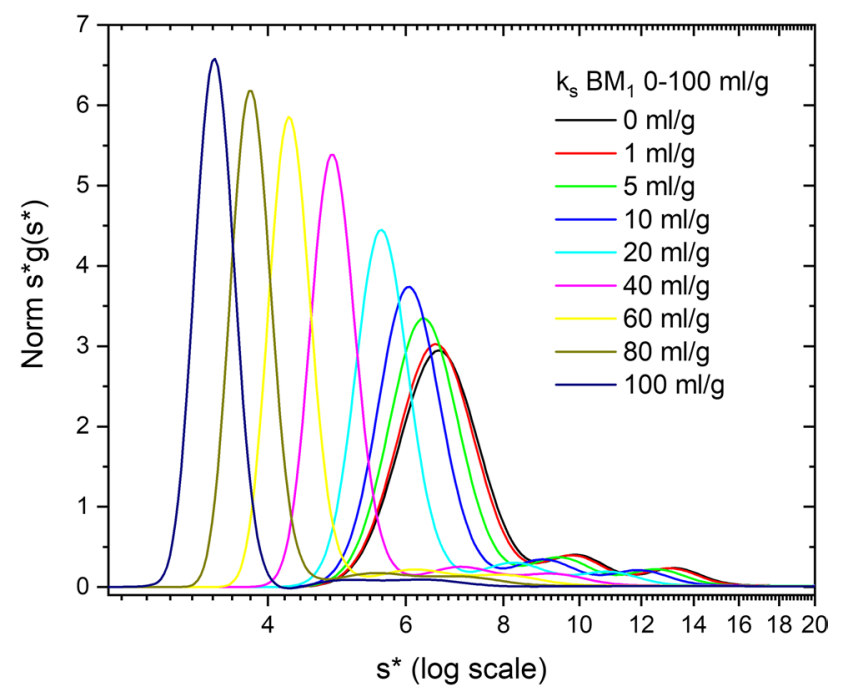

Fig. 4 Simulation of ABC model, at $10 \mathrm{mg} / \mathrm{ml}$ Simponi plus $10 \%$ dimer and $5 \%$ trimer aggregates, where all $k_{i j}$ and $B_{i j} M_{j}$ values (self and cross term) vary from 0 to $100 \mathrm{ml} / \mathrm{g}$. Data are plotted as normalized $s^{*} g\left(s^{*}\right)$ vs $s^{*}$ on a log scale 


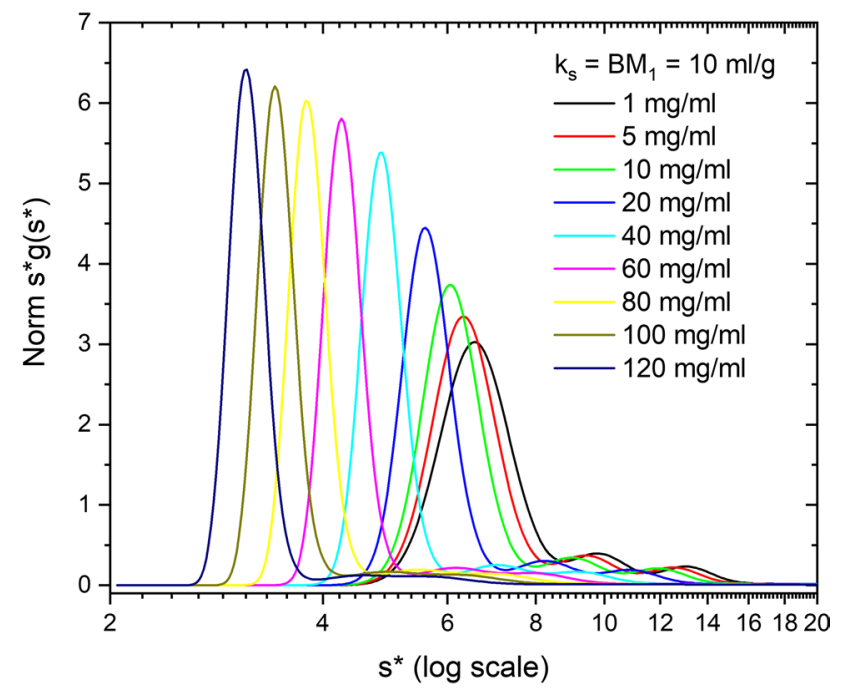

Fig. 5 Simulation of $\mathrm{ABC}$ model, at 1 to $120 \mathrm{mg} / \mathrm{ml}$ Simponi concentrations plus $10 \%$ dimer and 5\% trimer aggregates. Nonideality parameters $k_{i j}$ and $B_{i j} M_{j}$ values (self and cross term) are constrained to $10 \mathrm{ml} / \mathrm{g}$. Data are plotted as normalized $s^{*} g\left(s^{*}\right)$ vs $s^{*}$ on a log scale

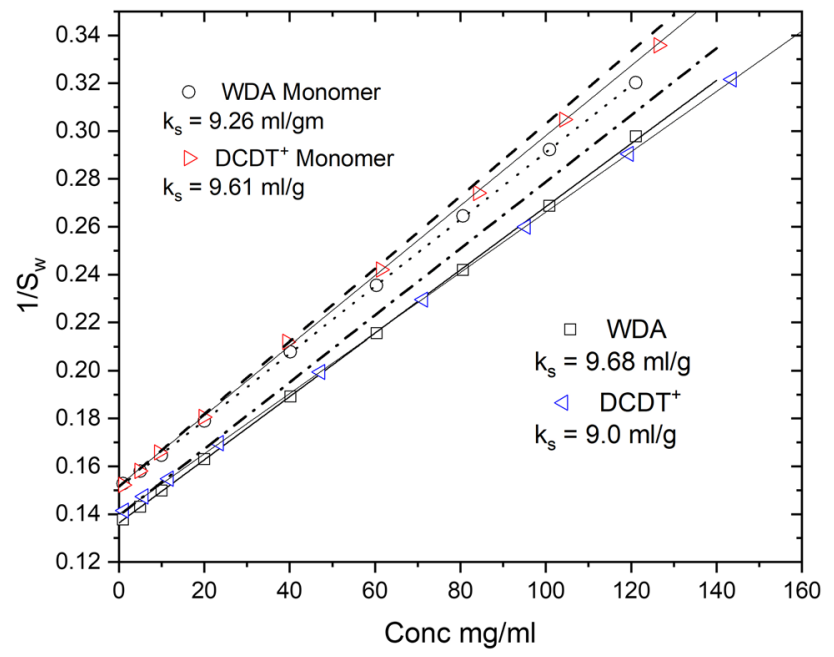

Fig. $61 / s$ vs $c$ plots of the data in Fig. 5 analyzed with $\mathrm{DCDT}^{+}$or WDA. The heavy dashed line represents monomer with an intercept at $6.6 \mathrm{~s}$ and $k_{s}=10 \mathrm{ml} / \mathrm{g}$. The heavy dot-dash line corresponds to a mixture of monomer-dimer-trimer with a $s^{0}{ }_{\mathrm{w}}=7.174$ and $k_{s}=10 \mathrm{ml} / \mathrm{g}$

(Figure S5A), causing significant spreading or back diffusion in the base region of nonideal samples that precludes using radial values too close to the base for WDA (Figure S5B). (It is worth noting that filling a cell to only 6.1 or $6.2 \mathrm{~cm}$ reduces the usable radial range for analysis and may be problematic for these highly nonideal systems, especially in FDS experiments where the base is already cutoff optically.)

These simulations emphasize three features of highly, nonideal systems due to either large $k_{i j}$ values or high concentrations. First, the boundary will be hyper-sharp during sedimentation, due to concentration dependence of $s_{\text {app }}$, and second, the base region will be very broad due to back diffusion into the plateau region caused by an increase in $D_{\text {app }}$. This second feature is entirely due to thermodynamic nonideality and reduces the radial region of data that can be analyzed by typical software packages. Thirdly, minor aggregates typically found in $\mathrm{mAb}$ solutions will experience significant broadening making their determination challenging for single sample analysis. In more heterogeneous solutions like serum, the high concentrations at the base cause density gradients that lead to banding of some lipoprotein species. (Analysis of serum samples by AUC FDS methods will be discussed in a future paper). It is worth noting that Figs. 4 and 5 look identical in normalized mode, but Fig. 5 is a concentration series, and thus the signal actually increases dramatically unless done in tracer mode (see below).

AUC data collected as a function of concentration are typically analyzed by linear plots of $s$ vs $c$ or $1 / s$ vs $c$ to extract $k_{s}$. The first plot is based upon the equation $s=s^{\mathrm{o}}\left(1-k_{s}^{\prime} c\right)$, a Taylor expansion of Eq. (1), while the second plot is the linear rearrangement of Eq. (1); $1 / s=1 / s^{0}+\left(k_{s} / s^{0}\right)^{*} c$. We have previously discussed the relationship between these two coefficients, $k_{s}$ and $k_{s}^{\prime}$ (Wright et al. 2018b). A $1 / s_{\mathrm{w}}$ vs $c$ plot of the data in Fig. 5 is presented in Fig. 6 using $s_{\mathrm{w}}$ of the full boundary, the WDA monomer peak positions or DCDT ${ }^{+}$ $s_{\mathrm{w}}$ of the monomer region. The data from WDA and DCDT ${ }^{+}$ are plotted vs total concentrations or concentrations corrected for radial dilutions (Patel et al. 2018). Matching the $s_{\mathrm{w}}$ with the appropriate concentration is the challenge in the analysis of mixtures by a graphical method. The extrapolated $s^{0}$ for monomers are reasonably close to the simulated value 6.6 S. The $k_{s}$ values approach the expected value of $10 \mathrm{ml} / \mathrm{g}$ but cannot precisely capture the more dynamic nonideality effect of radial dilution and demixing of the species (see "Discussion"). A simulation of just monomers ( $0 \%$ dimers, trimers) gives better but also not perfect estimates of $k_{s}$ (data not shown). The $s_{\mathrm{w}}$ data for the full boundary also approach the correct $s_{\text {w }}^{0}$ and $k_{s}$ values, but fail to capture the dynamics of nonideality and demixing (Kegeles and Gutter 1951; Patel et al. 2018).

Choosing the appropriate concentration and $s_{\mathrm{w}}$ seems to be the challenge in this linear analysis (Patel et al. 2018). To rigorously deal with sedimentation, radial dilution and species demixing (Kingsbury and Laue 2011), the data should be globally fit to an appropriate model as a function of concentration and time using finite-element solutions to the Lamm equation. To demonstrate the need for global fitting, we simulated FDS tracer data for this same $k_{s}, \mathrm{BM}_{1}$ model over the concentration range of $1-120 \mathrm{mg} / \mathrm{ml}$. A global SEDANAL fit of the data is presented in Fig. 7. The best fit returns $s=6.5994, k_{s}=10.0 \mathrm{ml} / \mathrm{g}$ and $\mathrm{BM}_{1}=9.99 \mathrm{ml} / \mathrm{g}$ with an $\mathrm{rms}=14.153$ which is the expected value for the added noise, 10 , increased by the $\sqrt{ } 2$ for the $\Delta \mathrm{C}$ method 


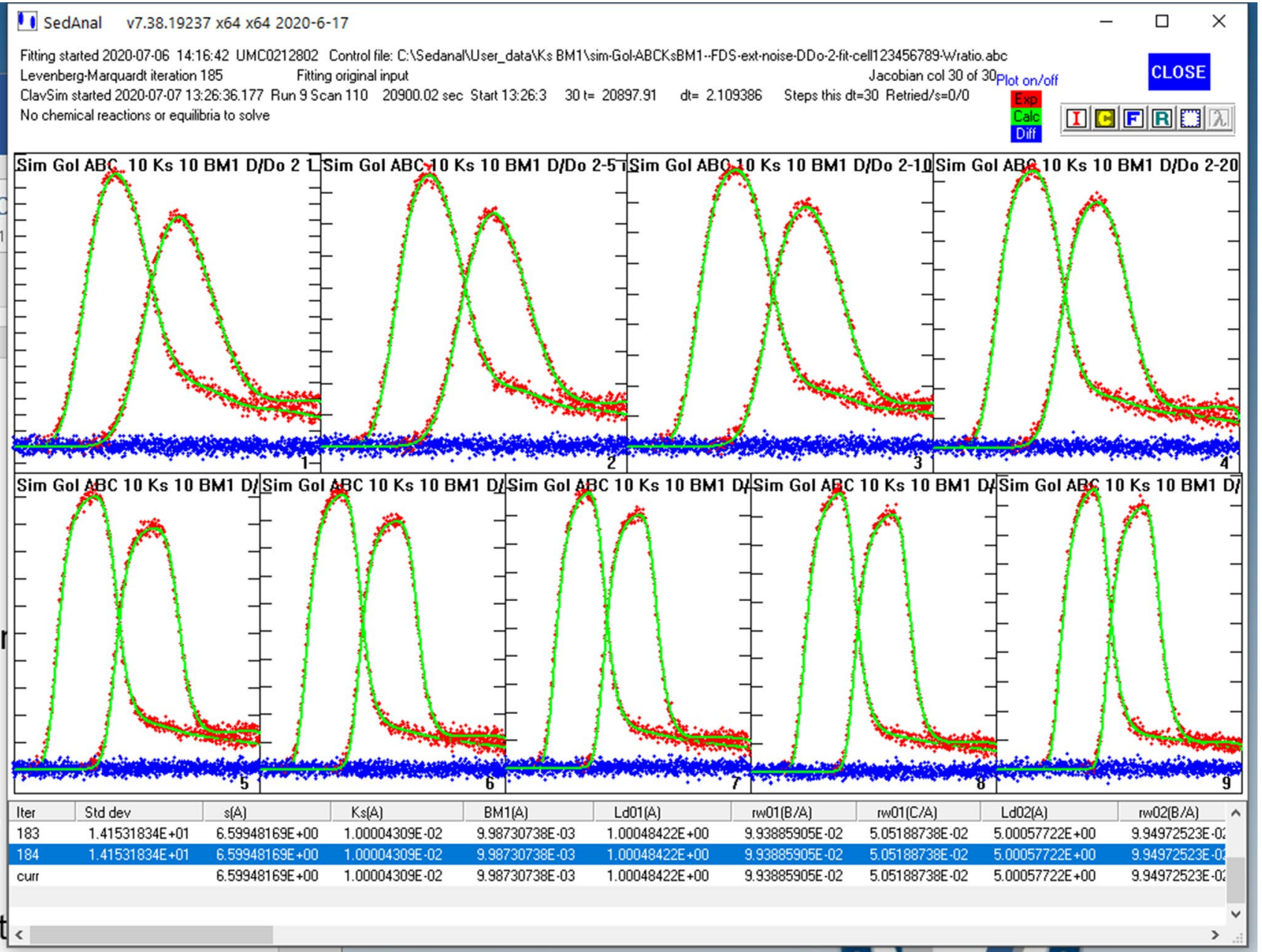

Fig. 7 A global SEDANAL fit of nine FDS data sets to an ABC- $k_{s}$ $\mathrm{BM}_{1}$ model with $10 \%$ dimer and $5 \%$ trimer aggregates. Data were simulated with a tracer amount of labeled Simponi corresponding to 1000 counts of monomer, and increasing amounts of unlabeled mAb.

used by SEDANAL. All the dimer and trimer weight ratios are correct within $1 \%$. Our conclusion is that a full concentration series, analyzed by global direct boundary fitting with a proper $k_{s}, \mathrm{BM}_{1}$ heterogeneous model is the most rigorous and accurate way to analyze high concentration AUC SV data. A bootstrap analysis of these data reveals very tight error bars as expected for simulated data (with 217,450 points; Table 1), but the error bars for $\mathrm{BM}_{1}$ are $\sim 6 \times$ larger than for $k_{s}$. This is consistent with our experimental observation that $\mathrm{BM}_{1}$ is much more difficult to measure than $k_{s}$ by $\mathrm{SV}$ analysis.

We observed that all mAbs exhibit weak self-association properties (Wright et al. 2018a, b; Yang et al. 2018). To include this in the analysis we have simulated a nonideal self-associating model at $10 \mathrm{mg} / \mathrm{ml}$ and increasing values of $K_{2}$ (Fig. 8). At $10 \mathrm{mg} / \mathrm{ml}$ and no association $\left(K_{2}=0\right)$ the curve clearly exhibits nonideality relative to the known
To produce a constant signal in tracer mode each apparent extinction coefficient is set to $1000 / c_{\mathrm{o}}$ where $c_{\mathrm{o}}$ is in $\mathrm{mg} / \mathrm{ml}$. In this in silico FDS tracer mode, extinction coefficient is held constant and concentration is fit

monomer s value. At $1000 \mathrm{M}^{-1}$ the main peak is still slightly nonideal meaning the monomer peak runs at less than $6.6 \mathrm{~s}$. The impact of this is that $k_{s \text {,app }}$ will be smaller than expected because it is masked by the association (Wright et al. 2018a; Yang et al. 2018). As $K_{2}$ increases the main peak shifts to the right indicating association, although it is worth noting the boundary is still nonideal, but now the nonideality is partially masked by weak association.

To investigate this further we simulated a nonideal concentration series for all four $K_{2}$ values (Fig. 9 presents data for $K_{2}=5000 \mathrm{M}^{-1}$ ) and then plotted all the data as $1 / s_{\mathrm{w}}$ vs $c$, corrected for radial dilution (Fig. 10). Up to $\sim 10 \mathrm{mg} / \mathrm{ml}$ the data shifts to increasing $s$ values, indicating association, and then shifts to lower $s$ values reflecting an increasing effect of nonideality (Stafford 1980). For weak association, the linear portions of the curve give a reduced apparent $k_{s}$ value consistent with masking of nonideality by association 


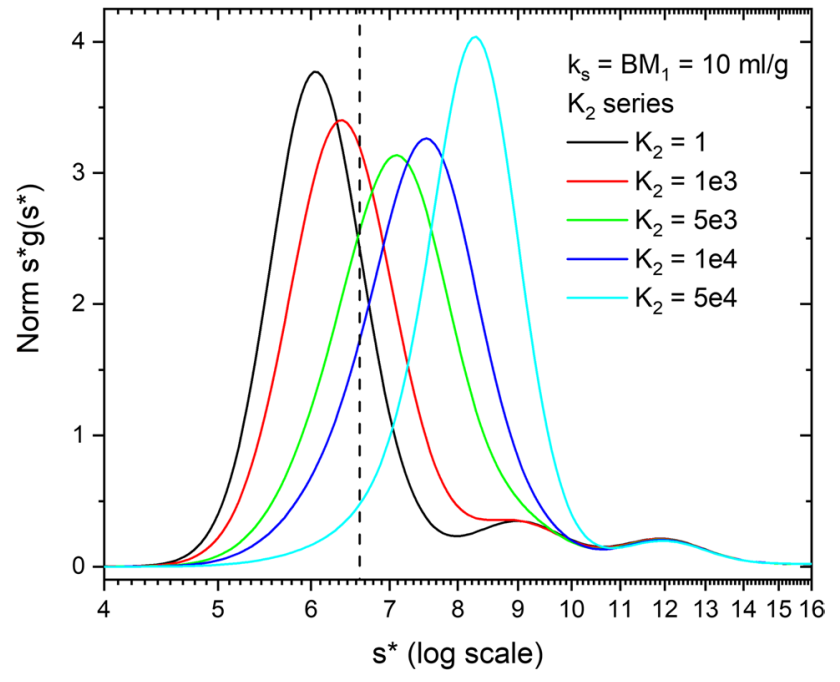

Fig. 8 Simulation of nonideal self-association models as a function of $K_{2}$ at $10 \mathrm{mg} / \mathrm{ml}, k_{s}=\mathrm{BM}_{1}=10 \mathrm{ml} / \mathrm{g}$. Results for $K_{2}$ values of 0,1000 , $5000,1 \mathrm{e} 4$, and $5 \mathrm{e} 4 \mathrm{M}^{-1}$ are presented. (Note these $K_{2}$ values in $\mathrm{M}^{-1}$ correspond to $K_{d}$ of $0,73.4,14.7,7.3$ and $1.47 \mathrm{mg} / \mathrm{ml}$, or $K_{2}(\mathrm{mg} /$ $\left.\mathrm{ml})^{-1}=2 \times K_{2}(\mathrm{M})^{-1} / 146,909\right)$ The monomer $s$ value is indicated by the vertical dashed line

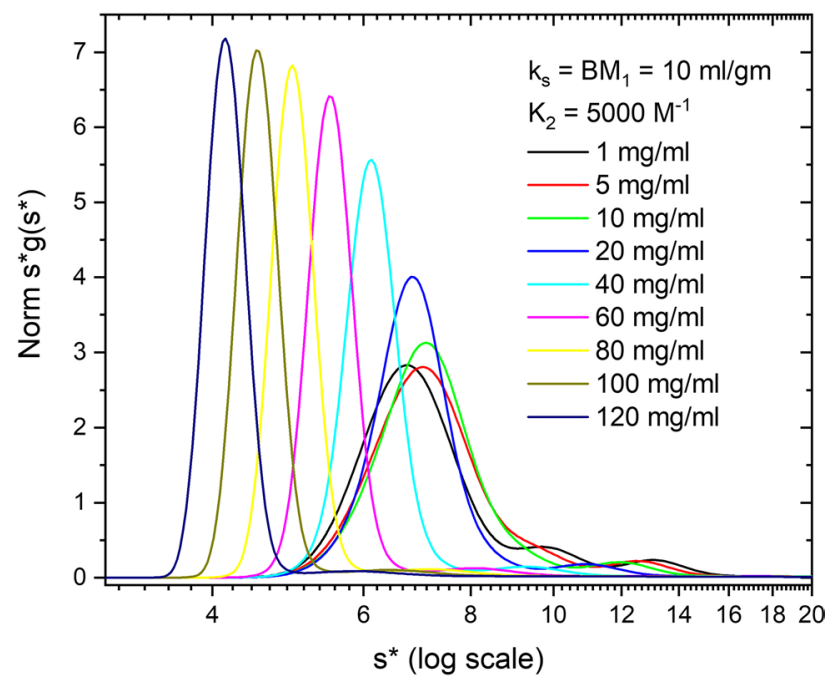

Fig. 9 Simulation of nonideal self-association $\left(k_{s}=\mathrm{BM}_{1}=10 \mathrm{ml} / \mathrm{g}\right.$, $\left.K_{2}=5000 \mathrm{M}^{-1}\right)$ as a function of concentration $(1-120 \mathrm{mg} / \mathrm{ml})$. The data are plotted as Norm $s^{*} g\left(s^{*}\right)$ vs $s^{*}$ on a $\log$ scale

(Wright et al. 2018a). Above $20 \mathrm{mg} / \mathrm{ml}$ nonideality becomes dominant, and with increasing $K_{2}$ values, the slope and intercept approach but do not equal $k_{s}$ and $s^{\mathrm{o}}$ values expected for the dimer. Nonideality and association are concentration-dependent and thus give different apparent answers at different concentrations. These results support the overlapping impact of radial dilution and fractionation during sedimentation on nonideality and association and the challenge of extracting these values by linear graphical methods. As

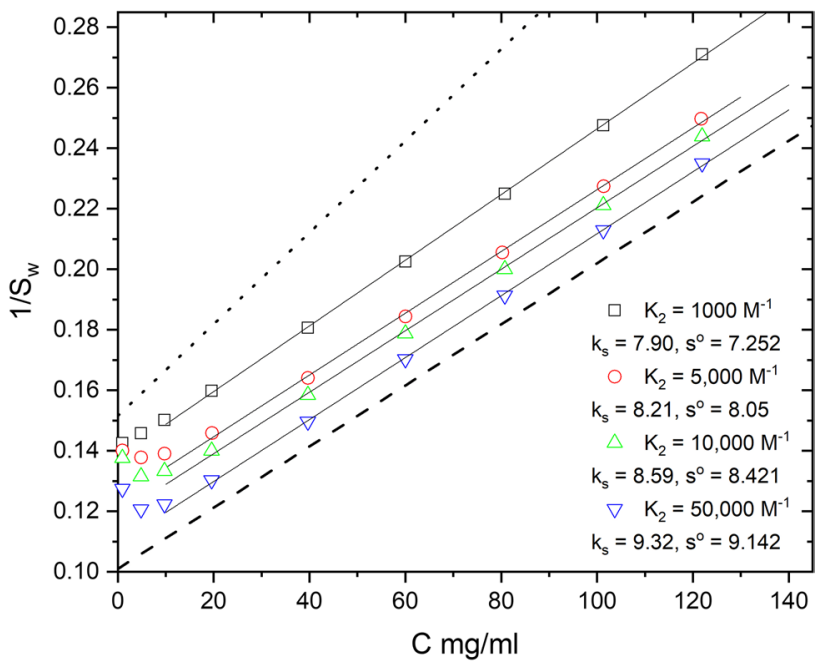

Fig. 10 A plot of $1 / s_{\mathrm{w}}$ vs concentration for $k_{s}, \mathrm{BM}_{1}, K_{2}$ data in Fig. 9 and repeated for data simulated with $K_{2}=1000,1 \mathrm{e}^{4}$ and $5 \mathrm{e}^{4} \mathrm{M}^{-1}$. The data were analyzed by integration of the full boundaries with $\mathrm{DCDT}^{+}$. The linear portions of the curves were fit to a straight line to extract apparent $k_{s}$ values and extrapolated $s^{\mathrm{o}}$ values. The dotted line is pure monomer with $s^{\circ}=6.6 \mathrm{~S}$ and $k_{s}=10 \mathrm{ml} / \mathrm{g}$. The dashed line is pure dimer with $s^{0}=9.9 \mathrm{~S}$ and $k_{s}=10 \mathrm{ml} / \mathrm{g}$

stressed above, the rigorous analysis of these data requires NLLS global fitting to the primary SV data.

To demonstrate the requirement for NLLS fitting, we simulated FDS tracer data for this same $k_{s}, \mathrm{BM}_{1}, K_{2}$ model over the concentration range of $1-120 \mathrm{mg} / \mathrm{ml}$ for a nonideal system with $K_{2}=5000 \mathrm{M}^{-1}$ (Fig. 11). The best global fit of these data returns $s=6.5989, k_{s}=10.00 \mathrm{ml} / \mathrm{g}$ and $\mathrm{BM}_{1}=10.06 \mathrm{ml} / \mathrm{g}, K_{2}=5008 \mathrm{M}^{-1}$ and an $\mathrm{rms}=14.106$. The weight ratio of dimer and trimer aggregates are returned correctly to less than $1 \%$. Bootstrap analysis reveals a $3 \times$ larger uncertainty on $\mathrm{BM}_{1}$ vs $k_{s}$ consistent with the observation above (Table 1; 184,340 points). The $\mathrm{BM}_{1}$ and $K_{2}$ data have a surprisingly small correlation coefficient $(R=0.34)$. Thus, we conclude that rigorous analysis of high concentration, nonideal, weak, associating systems requires global direct boundary fitting. At present only SEDANAL does global direct boundary analysis of AUC SV data to a nonideal associating model over this concentration range. There are other AUC approaches to analysis of high concentration SV data (Chaturvedi et al. 2018, 2019; Chaturvedi and Schuck 2019) that use a nonideal version of the $c(s)$ method $c_{\mathrm{NI}}(s)$. These methods estimate $k_{s}$ by a plot of $s_{\mathrm{w}}$ versus concentration, a problematic approach as discussed above, and do not do global fitting. Combining sedimentation equilibrium analysis to independently measure $\mathrm{BM}_{1}$ is certainly a reasonable approach, but it is not as useful for heterogeneous solutions like serum (see "Discussion"). Examples of additional fitting 


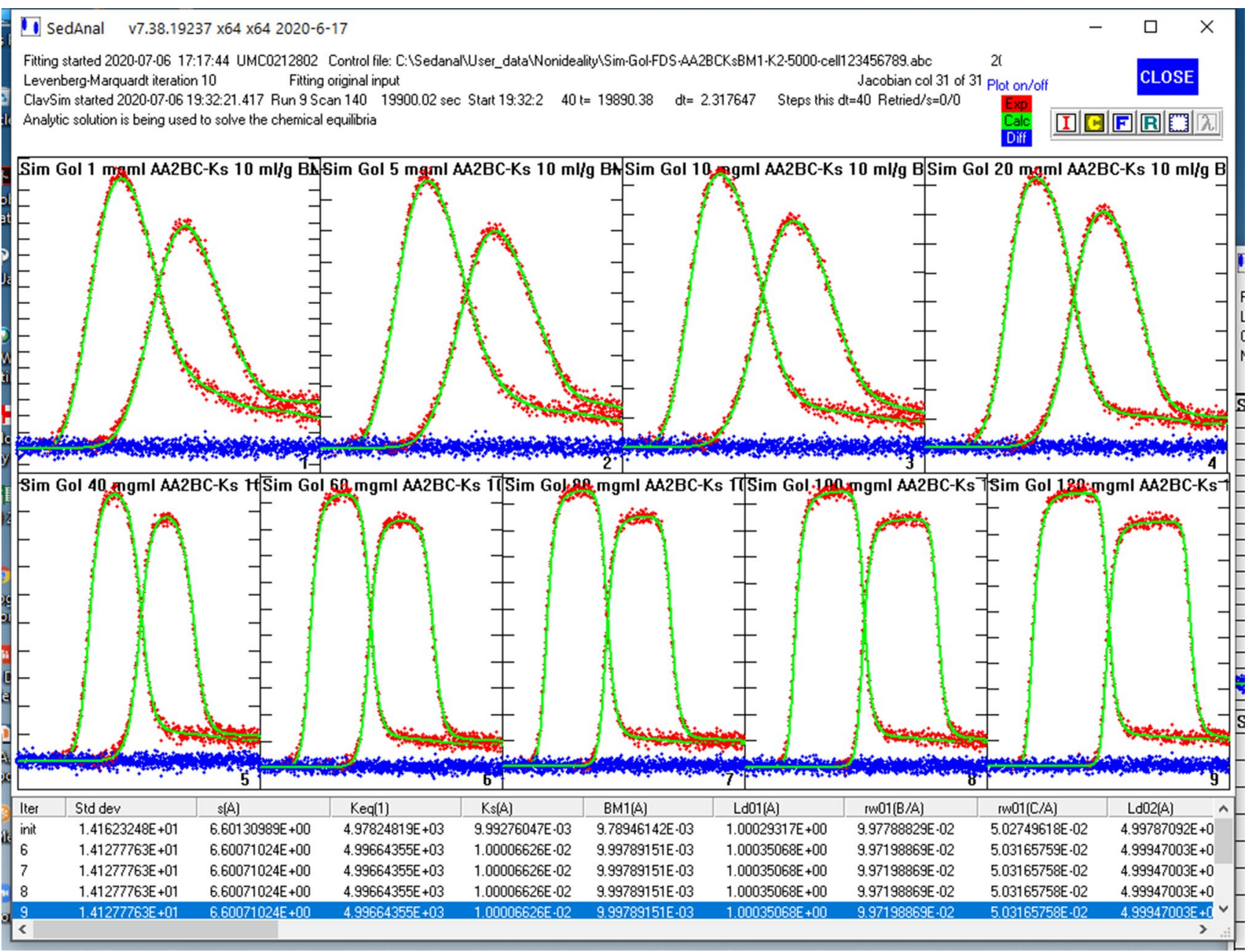

Fig. 11 A global SEDANAL fit of nine FDS data sets to an $\mathrm{AA}_{2} \mathrm{BC}-k_{s}-\mathrm{BM}_{1}-K_{2}$ model with $10 \%$ dimer and $5 \%$ trimer aggregates and $K_{2}=5000 \mathrm{M}^{-1}$. Data were simulated with a tracer amount of labeled Simponi corresponding to 1000 counts of monomer, and

requirements for real experimental data will be presented in a separate publication.

\section{Discussion}

The goal of this work is to present graphical distributions from SV simulations of nonideal mAbs solutions at high concentrations up to and exceeding the therapeutic concentration. This allows extraction of features that are direct consequence of hydrodynamic and thermodynamic nonideality. This should provide the opportunity to see the impact of $k_{s}$ and $\mathrm{BM}_{1}$ in $\mathrm{SV}$ data sets. Is the boundary hypersharp and running more slowly than expected? Is the base region much broader than typically observed? Is there evidence of negative gradients in the plateau region because of the JO effect, consistent with the presence of mixtures? The increasing amounts of unlabeled mAb. To produce a constant signal in tracer mode each apparent extinction coefficient is set to $1000 / c_{\mathrm{o}}$ where $c_{\mathrm{o}}$ is in $\mathrm{mg} / \mathrm{ml}$

phenomenological or empirical parameters $k_{s}$ and $\mathrm{BM}_{1}$ are best determined from their concentration-dependence. It is imperative that experiments be done as a function of loading concentration, the wider the range the better. We simulated data up to $120 \mathrm{mg} / \mathrm{ml}$ to exceed the therapeutic dose of Simponi. We also explored the range of $1-100 \mathrm{ml} / \mathrm{g}$ for $k_{s}$ and $\mathrm{BM}_{1}$. As discussed above, this range corresponds to compact, globular and moderately asymmetric proteins.

mAbs appear to have $k_{s}$ values in the range of $4-11 \mathrm{ml} / \mathrm{g}$ (Wright et al. 2018a, b; Yang et al. 2018), but this is sensitive to conditions, especially salt concentration, and methods of analysis. Weak self-association will mask $k_{s}$ and $\mathrm{BM}_{1}$ values, and thus proper models that include both nonideality and association are required (Wright et al. 2018a). Strongly associating $\mathrm{mAbs}$ are rare, but there are reports of much larger $k_{s}$ and $\mathrm{BM}_{1}$ values that may reflect asymmetric complex formation, linear chains of mAbs in an extended conformation 
(Liu et al. 1995; Hopkins et al. 2018). This discussion is based upon the assumptions outlined by Rowe (1977) that $k_{s}$ is due to swollen volume $V_{s}$ and $f / f_{\mathrm{o}}$ effects according to the equation $k_{s}=2 v\left(V_{s} / v+\left(f / f_{\mathrm{o}}\right)^{3}\right)$ where $v$ is vbar. The effects of $\mathrm{pH}$ and salt on $k_{s}$ are also of great interest. Yang et al. (2018) showed that increasing salt suppresses $\mathrm{mAb}$ association and allows $k_{s}$ values to increase and approach values of $10 \mathrm{ml} / \mathrm{g}$. Recently Chaturvedi et al. (2019) and Connolly et al. (2012) reported $k_{s}$ values $>20 \mathrm{ml} / \mathrm{g}$ in low salt conditions. Many investigations vary salt concentration and observe a suppression of association and reduction in viscosity (Yadev et al. 2012). Changes in $\mathrm{pH}$ have a surprisingly small impact. Direct charge measurements by membrane-confined electrophoresis (Moody and Shepard 2004) show a rather constant $\mathrm{mAb}$ charge as a function of $\mathrm{pH}$. They speculate that $\mathrm{mAbs}$ buffer charge due to $\mathrm{Cl}^{-}$or anion binding (Yadav et al. 2012; Yang et al. 2018).

The simulations presented here were done in absorbance mode in the absence of added noise. Interference could have worked equally well because in silico has no optical limitations. In practice absorbance experiments on typical mAbs at $280 \mathrm{~nm}$, assuming a generous useable range of $2 \mathrm{OD}$, are limited to $\sim 1.1 \mathrm{mg} / \mathrm{ml}$ in a $12 \mathrm{~mm}$ cell, to $\sim 13 \mathrm{mg} / \mathrm{ml}$ in a $1 \mathrm{~mm}$ cell. Collecting data at the UV minimum near $254 \mathrm{~nm}$ will expand this range, depending upon Trp/Tyr content, by a factor of 2. Interference has a much wider dynamic range and can be useful for AUC SV experiments up to $50 \mathrm{mg} /$ $\mathrm{ml}$ (Chaturvedi et al. 2018). Nanolytics has produced a new interference system (Schilling and Krause 2015) that claims to work up to $150 \mathrm{mg} / \mathrm{ml}$. Both of these claims about interference optics are dependent upon accurate optical focusing and conditions, especially speed, since fringe resolution is strongly dependent upon the gradient steepness. As shown in Figure S3, resolution of sedimenting species is strongly speed-dependent. Conditions also imply proper dialysis, the use of meniscus matching centerpieces, and may be influenced by formulation buffers. It is worth pointing out that both absorbance and interference are mostly limited to single component systems like pure mAbs.

Our approach to high concentration experiments uses FDS in a tracer mode, referred to as BOLTS or Biological On-Line Tracer Sedimentation by Laue (2009), where an Alexa-488 labeled mAb is run in a high concentration background of unlabeled mAb (Wright et al. 2018a). This allows no significant limit to the concentration ranges explored, besides solubility, and has the further advantage of being useful in serum, cell, and tissue extracts. As described above, this approach also allows a constant fluorescence signal to be used and thus provides better signal/noise characteristics for data analysis (Husain et al. 2015; Lyons et al. 2013). Our preference is $\sim 500-1000$ counts (out of 4096 $\max$ ), which is a function of label efficiency, but generally means 100-200 nM in typical mAb samples. This is the range of FDS data we simulate and fit in Figs. 7 and 11. The results are remarkably good with excellent accuracy and precision. Not all $\mathrm{mAb}$ are available to typical users over a range of $1-120 \mathrm{mg} / \mathrm{ml}$. Thus experiments may only be possible over $1-40$ or $1-20 \mathrm{mg} / \mathrm{ml}$ ranges. Fitting of these more limited concentration ranges also gives excellent results with the expected slightly wider uncertainty limits, especially in $\mathrm{BM}_{1}$ (Table 1). These considerations will be explored in subsequent experimental work.

It has been standard practice in the AUC field to extract $k_{s}$ values from concentration dependent SV analysis mostly through linear plots (Figs. 6 and 10; Kegeles and Gutter 1951; Creeth and Knight 1965; Rowe 1977; Li et al. 2012; Patel et al. 2018; Wright et al. 2018a, b). Although it has been proposed (Solovyova et al. 2001; Wright et al. 2018a, b), it is less common to extract $\mathrm{BM}_{1}$ values from SV analysis. Thus, it is worth asking, what is the consequence of not including $\mathrm{BM}_{1}$ in a direct boundary fit of data like Figs. 7 and 11 ? To investigate this we refit the $\mathrm{AA}_{2} \mathrm{BC}$ data in Table 1 without $\mathrm{BM}_{1}$. The $1-120 \mathrm{mg} / \mathrm{ml}$ data set returned an increase in $\mathrm{rms}\left(\mathrm{rms} / \mathrm{rms}_{\mathrm{o}}\right.$ where $\mathrm{rms}_{\mathrm{o}}$ is the fit with $\mathrm{BM}_{1}$ ) of $23 \%$, while for the $1-40 \mathrm{mg} / \mathrm{ml}$ data the $\mathrm{rms} / \mathrm{rms}_{\mathrm{o}}$ increased by $3.5 \%$, and for the $1-20 \mathrm{mg} / \mathrm{ml}$ data the $\mathrm{rms}$ increased by only $0.8 \%$. To achieve these fits the $s^{\mathrm{o}}$ values increased slightly while $K_{2}$ decreased (not shown). The surprising result was that the aggregated dimer to monomer fraction, $B / A$ in the model (Fig. 1), increased dramatically while the monomer fraction decreased. As mention above for Fig. 3, the impact of $\mathrm{BM}_{1}$ is to broaden the boundary making it appear heterogeneous. Thus, in the absence of $\mathrm{BM}_{1}$ the best fit now increases $B / A$, the aggregated dimer/ monomer fraction, to match the apparent heterogeneity of the boundary shape. Thus, not including $\mathrm{BM}_{1}$ in the fit appears to make aggregation seem to increase. To investigate the coupling between $\mathrm{BM}_{1}$ and the other parameters, we repeated the simulations without aggregated dimers and trimers, i.e. without species $B$ or species $C$, and then compared fitting with and without $\mathrm{BM}_{1}$ (Table 2). Now the $\mathrm{rms} / \mathrm{rms}_{\mathrm{o}}$ values were increased by $5.5 \%, 19 \%$ and $90 \%$, respectively, for the three concentration ranges. This was also matched by slightly larger s ${ }^{\mathrm{o}}$ values and smaller $K_{2}$ values, with $s^{\mathrm{o}}$ and $K_{2}$ values highly correlated, $R=0.85$. Thus, in the absence of aggregated dimers, the omission of $\mathrm{BM}_{1}$ in the fit has a larger impact on the best NLLS fit. These large $\mathrm{rms} / \mathrm{rms}_{\mathrm{o}}$ deviations are consistent with weak correlation between $\mathrm{BM}_{1}$ and the other parameters in the full fits $\left(K_{2}\right.$ vs $\mathrm{BM}_{1}, R=0.12 ; s$ vs $\mathrm{BM}_{1}, R=0.18 ; k_{s}$ vs $\left.\mathrm{BM}_{1}, R=0.14\right)$. Since BM1 seems to be nearly orthogonal to the other parameters, $s, k_{s}$ or $K_{2}$ cannot compensate for the absence of $\mathrm{BM}_{1}$ in the fit. In practice, this will be complicated by the actual presence of molecular heterogeneity due, for example, to variable glycosylation states or mixtures of other mAb conformations. 
Table 2 SEDANAL analysis of $\mathrm{AA}_{2} k_{s} \mathrm{BM}_{1} K_{2}=5000 \mathrm{FDS}$ model

\begin{tabular}{llllcl}
\hline $\begin{array}{l}\text { Concentrations } \\
(\mathrm{mg} / \mathrm{ml})\end{array}$ & $s$ & $k_{s} \mathrm{ml} / \mathrm{g}$ & $\mathrm{BM}_{1} \mathrm{ml} / \mathrm{g}$ & $K_{2} \mathrm{M}^{-1}$ & \multicolumn{1}{l}{$\mathrm{rms}$} \\
\hline $1-120$ & $6.6007(0.014 \%)$ & $9.9995(0.02 \%)$ & $9.9805(.17 \%)$ & $4989.3(0.22 \%)$ & 14.13 \\
& $6.7089(0.023 \%)$ & $10.26(0.05 \%)$ & - & $3723(0.45 \%)$ & $26.884(1.902)$ \\
$1-40$ & $6.6008(0.015 \%)$ & $10.001(0.045 \%)$ & $9.9419(.529 \%)$ & $4989.3(0.272 \%)$ & 14.128 \\
& $6.6333(0.015 \%)$ & $9.9618(0.099 \%)$ & - & $4407.3(0.334 \%)$ & $16.781(1.188)$ \\
$1-20$ & $6.6005(0.015 \%)$ & $10.011(0.14 \%)$ & $9.9126(1.36 \%)$ & $44998.8(0.368 \%)$ & 14.131 \\
& $6.6210(0.016 \%)$ & $9.6143(0.159 \%)$ & - & $4444.2(0.395 \%)$ & $14.905(1.055)$ \\
\hline
\end{tabular}

AA2 model is a reversible monomer-dimer association with nonideality $k_{s}$ and $\mathrm{BM}_{1}$. To explore the crosscorrelation of $\mathrm{BM}_{1}$ with $k_{s}$ and $K_{2}$, we re-simulated without species $\mathrm{B}$ or $\mathrm{C}$, meaning without aggregated dimer-aggregated trimer. Values in parentheses correspond to fractional error determined by a bootstrap analysis and correspond to one standard deviation. Note the ratio of best fit rms to the $\mathrm{rms}_{\mathrm{o}}$ of the fit with BM1 (values in parentheses under the rms column) is significantly larger without aggregated B and C included in the model to compensate for heterogeneity (see "Discussion"). These large $\mathrm{rms} / \mathrm{rms}_{\mathrm{o}}$ deviations are consistent with weak correlation between $\mathrm{BM}_{1}$ and the other parameters in the full fits $\left(K_{2} \mathrm{vs} \mathrm{BM}_{1}\right.$, $R=0.12 ; s$ vs $\left.\mathrm{BM}_{1}, R=0.18 ; k_{s} \mathrm{vs} \mathrm{BM}_{1}, R=0.14\right)$. Since $\mathrm{BM} 1$ seems to be orthogonal to the other parameters, $s, k_{s}$ or $K_{2}$ cannot compensate for the absence of $\mathrm{BM}_{1}$ in the fit
As previously reported, the FDS dynamic range in our hands is low $\mathrm{nM}$ to low $\mu \mathrm{M}$. Linearity of signal is the main concern (Lyons et al. 2013). In the case of associating systems, constant ratio of signal/mg upon association is assumed but must be proven. The main concern with using labeled samples is that the label does not interfere with the molecular behavior. It is possible that label-label interactions occur in complexes that quench or enhance the signal intensity. This is not usually seen in tracer experiments; experiments with $100 \%$ labeled material are more likely to exhibit quenching behavior depending upon the locations or separation of the labels in oligomeric complexes. (An example of quenching in FDS data will be presented elsewhere.)

The nonideality equations used here (1-4) are referred to as phenomenological equations meaning empirical or experimental. Thermodynamic nonideality, $\mathrm{BM}_{1}$, refers to excluded volume (Tanford 1961) and charge effects as described by the Donnan term in osmotic pressure (Scatchard 1946) or sedimentation equilibrium experiments (Roark and Yphantis 1971). Hydrodynamic nonideality, $k_{s}$, also refers to excluded volume and charge effects as reflected in the backflow during an SV experiment where displaced solvent must replace the volume a macromolecule vacates during sedimentation. The sedimenting particle has an effective solvated volume $V_{s}$ that reflects hydration, shape through an $f / f_{\mathrm{o}}$ term, and the entrained solvent captured within the Debye length (Fuoss 1959; Fuoss and Onsager 1932; Rowe 1977, 1992). It is worth noting that the effective charge is much smaller than typically assumed due to charge screening and anion binding (Laue 2011; Laue and Shire 2020). This in principle reflects the Stokes radius of the effective electroneutral sphere. We are aware that a good $k_{s}$ model system that controls for shape and charge would be useful here for investigating the dependence of $k_{s}$ on charge. Our purpose is not to assign theoretical values but rather to present the impact of typical empirical values for these parameters. It is more important that the impact of these values is graphically presented, and that their measurement by NLLS fitting to proper models, nonideality plus association, be clearly outlined.

It is generally assumed that the correct concentration scale for high concentration work is volume fraction (Ross and Minton 1977) and recent AUC studies on high concentration use the volume fraction $\Phi$ scale (Chaturvedi et al. 2018; Chaturvedi and Schuck 2019). The conversion is in principle a linear transformation, as simple as $\nu c$ (Broide et al. 1991), but more realistically $V_{s} c$ where the swollen or effective volume is used (Rowe 1992; Chaturvedi and Schuck 2019). At high volume fraction the shape and packing considerations may become important for mAbs (Garidel et al. 2017). The conversion of weight concentration to volume fraction can be verified from intrinsic viscosity measurements: $\Phi_{\text {eff }}=[\eta] c / 2.5$, where 2.5 is for spheres (Cantor and Schimmel 1980). Therefore, we are currently making viscosity measurements on mAbs and serum proteins and will present those data in a subsequent publication along with AUC SV measurements. It has also been observed that mAbs deviate from linear viscosity behavior above approximately $50 \mathrm{mg} / \mathrm{ml}$. (The Shire group has investigated the impact of association on viscosity and the problems it causes for drug delivery by injection (Liu et al. 2005; Yadav et al. 2011b, 2012).) We have confirmed these nonlinear viscosity observations and furthermore observe similar deviations in $s_{\mathrm{w}}$ vs concentration plots. This has implications for SEDANAL analysis and requires a second order term, $k_{s 2} c^{2}$, in the $s / s_{0}$ and $D / D_{\mathrm{o}}$ phenomenological Eqs. (3, 4). This and a higher order 3 rd virial coefficient, $\mathrm{CM}_{1}$, were previously incorporated into SEDANAL. The polymer field refers to this nonlinear deviation as clustering or low energy attraction $(\sim 5 \mathrm{kT}$ or $3 \mathrm{kcal} / \mathrm{mol})$ near the boundary 
for liquid-liquid phase separation (Fiore et al. 2018). Clustering is clearly a distinct phenomena to the self-association we describe here.

Acknowledgements Supported by UMC AUC Facility. This work was presented at the 24th International AUC Workshop and Symposium, Christchurch, New Zealand. We thank Dave Bain, Tom Laue and Sharon Lobert for constructive comments.

Author contributions JJC designed and performed the simulations. JJC and WFS analyzed and interpreted the data, and wrote the manuscript. WFS and PJS wrote the SEDANAL software modifications. RTW provided simulations in the early stages of this work. All authors did see and have agreed to the final version of the manuscript.

\section{Compliance with ethical standards}

Conflict of interest The authors declare that they have no competing interests.

Open Access This article is licensed under a Creative Commons Attribution 4.0 International License, which permits use, sharing, adaptation, distribution and reproduction in any medium or format, as long as you give appropriate credit to the original author(s) and the source, provide a link to the Creative Commons licence, and indicate if changes were made. The images or other third party material in this article are included in the article's Creative Commons licence, unless indicated otherwise in a credit line to the material. If material is not included in the article's Creative Commons licence and your intended use is not permitted by statutory regulation or exceeds the permitted use, you will need to obtain permission directly from the copyright holder. To view a copy of this licence, visit http://creativecommons.org/licenses/by/4.0/.

\section{References}

Berkowitz SA (2006) Role of analytical ultracentrifugation in assessing the aggregation of protein biopharmaceuticals. AAPS J 8:E590-E605

Broide ML, Berland CR, Pande J, Ogun O, Benedek GB (1991) Binary-liquid phase separation of lens protein solutions. PNAS 88:5660-5664

Cantor CR, Schimmel PR (1980) Biophysical chemistry, chapter 10-3. WH Freeman and Company, New York

Chaturvedi SK, Schuck P (2019) A reappraisal of sedimentation nonideality coefficients for the analysis of weak interactions of therapeutic proteins. AAPC J 21:35-35

Chaturvedi SK, Ma J, Brown PH, Zhao H, Schuck P (2018) Measuring macromolecular size distributions and interactions at high concentrations by sedimentation velocity. Nat Commun 9:4415-4424

Chaturvedi SK, Sagar V, Zhao H, Wistow G, Schuck P (2019) Measuring ultra-weak protein self-association by non-ideal sedimentation velocity. JACS 141:2990-2996

Claverie JM (1976) Sedimentation of generalized systems of interacting particles. III Concentration-dependent sedimentation and extension to other transport methods. Biopolymers 15:843-857

Connolly BD, Petry C, Yadav S, Demeule B, Ciaccio N, Moore JMR, Shire SJ, Gokarn YR (2012) Weak interactions govern the viscosity of concentrated antibody solutions: high-throughput analysis using the diffusion interaction parameter. Biophys J 103:69-78
Correia JJ, Stafford WF (2015) Sedimentation velocity: a classical perspective. Methods Enzymol (J Coles Ed) 562:49-80

Correia JJ, Johnson ML, Weiss GH, Yphantis DA (1976) Numerical study of the Johnston-Ogston effect in two component systems. Biophys Chem 5:255-264

Correia JJ, Lyons DF, Sherwood P, Stafford WF (2016) Techniques for dissecting the Johnston-Ogston Effect. In: Uchiyama S, Arisaka F, Laue T, Stafford W (eds) Analytical ultracentrifugation-instrumentation, analysis and applications. Springer, Berlin, pp 243-262

Creeth JM, Knight CG (1965) On the estimation of the shape of macromolecules from sedimentation and viscosity measurements. BBA 102:549-558

Demeule B, Shire SJ, Liu J (2009) A therapeutic antibody and its antigen form different complexes in serum than in phosphate-buffered saline: a study by analytical ultracentrifugation. Anal Biochem 388:279-287

Fiore AM, Wang G, Swan JW (2018) From hindered to promoted settling in dispersions of attractive colloids: simulation, modeling, and application to macromolecular characterization. Phys Rev Fluids 3:063302

Fujita H (1962) Mathematical theory of sedimentation analysis. Academic Press, New York

Fuoss RW (1959) The velocity field in electrolytic solutions. J Phys Chem 63:633-636

Garidel P, Kuhn AB, Schafer LV, Karow-Zwick AR, Blech M (2017) High-concentration protein formulations: how high is high? Eur J Pharm Biopharm 119:353-360

Harding SE, Johnson P (1985) The concentration dependence of macromolecular parameters. Biochem J 231:543-547

Hopkins MM, Lambert CA, Bee JS, Parupudi A, Bain DL (2018) Determination of interaction parameters for reversibly selfassociating antibodies: a comparative analysis. J Pharm Sci 107:1820-1830

Husain B, Hesler S, Cole JL (2015) Regulation of PKR by RNA: formation of active and inactive dimers. Biochemistry 54:6663-6672

Johnston JP, Ogston AG (1946) A boundary anomaly found in the ultracentrifugal sedimentation of mixtures. Trans Faraday Soc 42:789-799

Kegeles G, Gutter FJ (1951) The determination of sedimentation constants from Fresnel diffraction patterns. JACS 73:3770-3777

Kingsbury JS, Laue TM (2011) Fluorescence-detected sedimentation in dilute and highly concentrated solutions. Methods Enzymol 492:283-304

Kroe RR, Laue TM (2009) NUTS and BOLTS: applications of fluorescence-detected sedimentation. Anal Biochem 390:1-13

Laue TM (2011) Proximity energies: a framework for understanding concentrated solutions. J Mol Recognit 25:165-173

Laue TM, Shire SJ (2020) The molecular interaction process. J Pharm Sci 109:154-160

Liu J, Lester P, Builder S, Shire SJ (1995) Characterization of complex formation by humanized anti-IgE monoclonal antibodies and monoclonal human IgE. Biochemistry 34:10474-10482

Liu J, Nguyen MDH, Andya JD, Shire SJ (2005) Reversible selfassociation increases the viscosity of a concentrated monoclonal antibody in aqueous solution. J Pharm Sci 94:1928-1940

Liu J, Yadav S, Andya J, Demeule B, Shire SJ (2015) Analytical ultracentrifugation and its role in development and research of therapeutic proteins. Methods Enzymol (J Coles Ed) 562:441-476

Li Y, Stafford WF, Hesselberg M, Hayes D, Wu Z, Byrne M (2012) Characterization of the self-association of human interferon- $\alpha 2 b$, albinterferon- $\alpha 2 b$, and Pegasys. J Pharm Sci 101:68-80

Lyons DF, Lary JW, Husain B, Correia JJ, Cole JL (2013) Are fluorescence - detected sedimentation velocity data reliable? Anal Biochem 437(2):133-137 
MacGregor IK, Anderson AL, Laue TM (2004) Fluorescence detection for the XLI analytical ultracentrifuge. Biophys Chem 108:165-185

Moody TP, Shepard HK (2004) Nonequilibrium thermodynamics of membrane-confinement electrophoresis. Biophys Chem 108:51-76

Onsager L, Fuoss RW (1932) Irreversible processes in electrolytes diffusion, conductance, and viscous flow in arbitrary mixtures of strong electrolytes. J Phys Chem 36:2689-2778

Patel TR, Winsor DJ, Scott DJ (2018) Allowance for radial dilution in evaluating the concentration dependence of sedimentation coefficients for globular proteins. Eur Biophys J 47:291-295

Philo JS (2003) Characterizing the aggregation and conformation of protein therapeutics. Am Biotechnol Lab 21:22-26

Philo JS (2006) Improved methods for fitting sedimentation coefficient distributions derived by time-derivative techniques. Anal Biochem $354: 238-246$

Philo JS (2009) Critical review of methods for size characterization of non-particulate protein aggregates. Curr Pharm Biotechnol 10:359-372

Roark DE, Yphantis DA (1971) Equilibrium centrifugation of nonideal systems. The Donnan effect in self-associating systems. Biochemistry 10:3241-3249

Ross PD, Minton AP (1977) Hard quasispherical model for the viscosity of hemoglobin solutions. BBRC 76:971-976

Rowe AJ (1977) The concentration dependence of transport processes: a general description applicable to sedimentation, translational diffusion, and viscosity coefficients of macromolecular solutes. Biopolymers 16:2595-2611

Rowe AJ (1992) The concentration dependence of sedimentation. In: Harding SE, Rowe AJ, Horton JC (eds) Analytical ultracentrifugation in biochemistry and polymer science. Royal Society of Chemistry, London, pp 394-406

Rowe AJ (2011) Ultra-weak reversible protein-protein interactions. Methods 54:157-166

Saluja A, Fesinmeyer RM, Brems DN, Gokarn YR (2010) Diffusion and sedimentation interaction parameters for measuring the second virial coefficient and their utility as predictors of protein aggregation. Biophys J 99:2657-2665

Scatchard G (1946) Physical chemistry of protein solutions. I derivation of the equations for the osmotic pressure. JACS 68:2315-2319

Schilling K, Krause F (2015) Analysis of antibody aggregate content at extremely high concentrations using sedimentation velocity with a novel interference optics. PLOS ONE 10:e0120820

Sherwood PJ, Stafford WF (2016) SEDANAL: model-dependent and model-independent analysis of sedimentation data. In: Uchiyama A (ed) Analytical ultracentrifugation. Royal Society of Chemistry, London, pp 81-102

Shire SJ, Shahrokh Z, Liu J (2004) Challenges in the development of high protein concentration formulations. J Pharm Sci 93:1390-1402

Solovyova A, Schuck P, Costenaro L, Ebel C (2001) Non-ideality by sedimentation velocity of halophilic malate dehydrogenease in complex solvents. Biophys J 81:1868-1880
Stafford WF (1980) Graphical analysis of nonideal monomer N-mer, isodesmic, and Type II indefinite self-associating systems by equilibrium ultracentrifugation. Biophys J 29:149-166

Stafford WF (1992) Boundary analysis in sedimentation transport experiments: a procedure for obtaining sedimentation coefficient distributions using the time derivative of the concentration profiles. Anal Biochem 203:295-301

Stafford WF (2016) Analysis of nonideal, interacting, and noninteracting systems by sedimentation velocity analytical ultracentrifugation. In: Uchiyama S, Arisaka F, Stafford WF, Laue T (eds) Analytical ultracentrifugation: instrumentation software and applications. Royal Society of Chemistry, London, pp 463-482

Stafford WF, Braswell EH (2004) Sedimentation velocity, multi-speed method for analyzing polydisperse solutions. Biophys Chem 108:273-279

Stafford WF, Sherwood PJ (2004) Analysis of heterologous interacting systems by sedimentation velocity: curve fitting algorithms for estimation of sedimentation coefficients, equilibrium and kinetic constants. Biophys Chem 108:231-243

Tanford C (1961) Physical chemistry of macromolecules. Wiley, New York

Todd GP, Haschemeyer RH (1981) General solutions to the inverse problem of the differential equation of the ultracentrifuge. PNAS 78:6739-6743

Wright RT, Hayes DB, Stafford WF, Sherwood PJ, Correia JJ (2018) Pre-clinical biophysical characterization of therapeutic antibodies in human serum by analytical ultracentrifugation. Anal Biochem 550:72-83

Wright RT, Hayes DB, Sherwood PJ, Stafford WF, Correia JJ (2018) AUC measurements of diffusion coefficients of monoclonal antibodies in the presence of human serum proteins. Eur Biophys $\mathrm{J}$ 47:709-722

Yadav S, Sreedhara A, Kanai S, Liu J, Lien S, Lowman H, Kalonia DS, Shire SJ (2011) Establishing a link between amino acid sequences and self-association and viscoelastic behavior of two closely related monoclonal antibodies. Pharm Res 28:1750-1764

Yadav S, Scherer TM, Shire SJ, Kalonia DS (2011) Use of dynamic light scattering to determine second virial coefficient in a semidilute concentration regime. Anal Biochem 411:292-296

Yadav S, Scherer TM, Shire SJ, Kalonia DS (2012) Viscosity behavior of high-concentration monoclonal antibody solutions: correlation with interaction parameter and electroviscious effects. J Pharm Sci 101:998-1011

Yang D, Correia JJ, Stafford WF, Roberts CJ, Singh S, Hayes D, KroeBarrett R, Nixon A, Laue TM (2018) Weak IgG self- and heteroassociation characterized by fluorescence analytical ultracentrifugation. J Protein Sci 27:1334-1348

Publisher's Note Springer Nature remains neutral with regard to jurisdictional claims in published maps and institutional affiliations. 